\title{
OUTCOMES AFTER LAPAROSCOPIC SLEEVE GASTRECTOMY FOR MORBIDLY OBESE PATIENTS
}

\author{
Amr Elsherif \\ Department of Clinical and Experimental Surgery, Medical Research Institute, Alexandria University
}

\section{ABSTRACT:}

Introduction: laparoscopic Sleeve gastrectomy has become reportedly one of the most effective standalone bariatric procedures during the past decade. The intermediate and longterm outcomes are being studied by many researchers.

Aim: To study the short and intermediate term results of LSG in a group of Egyptian morbidly obese patients as regards mean decrease in body mass index (BMI), \% of excessive weight loss (\% EWL), and resolution of comorbidities.

Results: One hundred and forty patients, 92 females $(66 \%)$ and 48 males $(34 \%)$, with a mean BMI of $49 \pm 7.4 \mathrm{~kg} / \mathrm{m} 2$ contributed in our study. Obesity related comorbidities were reported in some of our patients in the form of Type II diabetes mellitus $(n=43)$, hypertension $(\mathrm{n}=36)$, hyperlipidemia $(\mathrm{n}=24)$, and osteoarthritis $(n=30)$. All patients underwent laparoscopic sleeve gastrectomy. All patients completed a follow up period of two years. At two years period the mean BMI decreased to $30 \pm 5.9 \mathrm{~kg} / \mathrm{m} 2$ (p-value $<0.0001)$. While the mean $\%$ of EWL was $73 \pm 10.3 \%$. We reported complete resolution of disease in $90.6 \%, 94.4 \%$, and $83.3 \%$ of Type II diabetes mellitus, hypertension, and hyperlipidemia patients respectively.

Conclusion: laparoscopic sleeve gastrectomy is associated with significant decrease in mean BMI, and \% of EWL in morbidly obese patients during the short and intermediate terms. In addition, it is associated with resolution of obesity related comorbidities in high percentage of patients.

Key Words: Morbid obesity, Bariatric surgery, Laparoscopic sleeve gastrectomy, Body mass index (BMI). Tvpe II diabetes mellitus. Hvpertension

\section{INTRODUCTION}

$\mathrm{Ob}$ besity has become a worldwide epidemic according to recent WHO reports. More than $39 \%$ of the adult population all over the world are overweight and more than $13 \%$ are obese. ${ }^{(1)}$ Obesity has been associated with several health disorders that affect general health and life expectancy. ${ }^{(2,3)}$ There has been agreement that surgery is the best and most durable treatment for morbidly obese patients who failed other lines of management. (4) Laparoscopic Sleeve gastrectomy (LSG) has gained worldwide popularity as a standalone procedure among the armamentarium of morbid obesity surgeries during the last decade ${ }^{(5)}$.Many centers have adopted LSG as their primary technique and have reported various outcomes. (6-9) In this study, we report our short and intermediate term results of LSG in a group of Egyptian patients as regards \% of excessive weight loss (\% EWL), \% decrease in body mass index (BMI), and resolution of co-morbidities.

\section{PATIENTS AND METHODS:}

We conducted a prospective study, which included 140 morbidly obese patients who were referred to the bariatric surgery unit, department of surgery, medical research institute, Alexandria University in the period between 2010 and 2014. The ethics committee in the institution approved the study after being reviewed by board. All the patients signed an informed consent of participation in the study.

Patients were recruited in our study according the guidelines of the international federation of the surgery of obesity (IFSO) and the European Association of the study of Obesity (EASO). ${ }^{(10)}$ This included patients with age ranging between $18-70$ years, BMI $>40 \mathrm{~kg} / \mathrm{m}^{2}$ with or without comorbidities, or $>35 \mathrm{~kg} / \mathrm{m}^{2}$ with comorbidities, passage through unsuccessful weight losing programs, patients who understood the operation, it's consequences and were willing to comply with it. We excluded high surgical risk patients, patients with uncontrolled depression and those with other mental disorders.

All patients underwent a complete history taking and physical examination. Diagnostic workup included gastrographin meal study, abdominal ultrasonography, X-ray chest, electrocardiogram, complete blood count, coagulation profile, thyroid profile, lipid profile, blood urea nitrogen (BUN), creatinine, and evaluation of liver functions and coagulation profile. Consultation with cardiologists, pulmonologists and anesthetists was done. All the patients signed an informed written consent. All patients received prophylaxis against deep vein thrombosis (DVT) 12 hours before the operation. 
Under general anesthesia and in anti-Trendelenburg position, the abdominal cavity was accessed through five trocars technique. After abdominal exploration, the greater curvature of the stomach was devascularized starting at $2-4 \mathrm{~cm}$ from the pylorus, and extending proximally up to the angle of His and the left crus. The short gastric vessels were sealed and divided to dissect the stomach from the spleen. The posterior wall and the fundus of the stomach were properly dissected to avoid sagging of the fundus (figure 1). Using an Endo-GIA linear stapler (Covidien, USA) and $60 \mathrm{~mm}$ long staple loading units (starting with one or two 4.8 / green units to perform partial antrectomy and four to five $3.5 /$ blue units for the body and extending up till the fundus), we tailored a gastric conduit over a 36 Fr bougie (figure 2). We tested the integrity of the staple line using methylene blue solution injection into the lumen of the gastric conduit. At the end of the operation, we performed good hemostasis, retrieval of the resected part, insertion of a tube drain into the left sub diaphragmatic space then closure of the abdominal wall wounds in layers. ${ }^{(11)}$

On the first post-operative day, and after clinical assessment, patients resumed oral fluids. Patients were discharged on anti-biotics, anti-coagulation, and analgesics. Follow up of the patients was performed on regular intervals. Change in BMI, \% of EWL, and resolution of co-morbidities were assessed after six months, one year and after two years.

\section{STATISTICAL ANALYSIS}

We used SPSS software version 18.0 for data analysis. To assess the significance of the resolution rates of different co-morbidities after the operations we used McNemar Chi-square test. Mean \pm SD. and Paired samples t-test were used the comparison of change in BMI and \% of EWL before and after surgery. The level of confidence was determined at $95 \%$ and P-values $<0.05$ were considered significant. Resolution of comorbidities was calculated using the following formula

\section{Resolution Rate \\ number of diseased preopeatively - number of diseased postoperatively number of diseased preoperatively

Percentage of Excessive weight lost was calculated using the following formula:

$\% \mathrm{EWL}=\frac{\text { preoperative weight }- \text { postoperative weight }}{\text { preoperative weight }- \text { Target weight }} X 100$

\section{RESULTS}

One hundred and forty patients, 92 females (66\%) and 48 males $(34 \%)$ contributed in our study. The age of the patients ranged from 17-58 years with a mean of $36 \pm$ 8.36. The BMI ranged from $38-73 \mathrm{~kg} / \mathrm{m}^{2}$ with a mean of $49 \pm 7.4$. The weight of the patients ranged from $97-198$ $\mathrm{kg}$ with a mean of $112 \pm 27 \mathrm{~kg}$. The frequency of preoperative co-morbidities are expressed in table 1. All the patients completed the 24 months follow up period.

The operative time ranged from 110 - 240 minutes with a mean of $124 \pm 12$. Twenty six patients (18.6\%) had intraoperative bleeding. Four patients had bleeding from the gastroepiploic vessels that was controlled by bipolar cautery and under running 3/0 absorbable sutures. Five patients had bleeding from the short gastric vessels that were controlled by bipolar cautery and endo clips. While seventeen patients had bleeding from the stable line of the gastric conduit, for which we used endo clips and figure of eight 3/0 absorbable sutures for control. No patient required blood transfusion. Ten patients $(7.1 \%)$ had left lobe of the liver visceral surface minor tear with transient bleeding due to retraction force. None of them required intervention. All procedures were completed laparoscopically (Table 2).

During the post-operative period, two patients $(1.4 \%)$ had signs of pulmonary embolism during the first week after discharge although they received prophylactic dose of low molecular weight (LMW) heparin, in the form of severe dyspnea, tachypnea, and low arterial oxygen saturation. D-dimer was above three thousand in both patients. They were re-admitted and treated by therapeutic dose of LMW heparin, oxygen mask, good hydration, and then oral anticoagulants.

We had three cases of leakage $(2.1 \%)$ that occurred between the fourth and the six post-operative days. The patients presented to us with severe upper abdominal and retrosternal pain that referred to the back and the shoulders, with high-grade fever. The leak was early diagnosed by CT-scan of the lower chest and abdomen using oral and intravenous contrast, which revealed leakage of dye into the left subdiaphragmatic space and luckily no free intra-abdominal collections. Blood tests revealed elevated leukocytic count, C-reactive protein, and sedimentation rate in all of the patients. The three patients were readmitted, received intra venous antibiotics, good hydration. The abdominal collection was drained percutaneously under ultrasound guidance and pigtail catheter was inserted to sustain adequate drainage. The leak was treated endoscopically by the insertion of a mega $23 \mathrm{~cm}$ long fully covered metallic stent to isolate the area of leak and to bypass the gastric conduit until the second part of the duodenum. The patients resumed oral fluids one day after, and were discharged after improvement of sepsis markers. Regular endoscopic follow up was performed and the stents were removed after four to six weeks with no chronic fistula formation (Table 2).

Dysphagia with or without odynophagia was reported by fifteen patients $(10.7 \%)$. Gastrographin swallow studies revealed no strictures, and endoscopic examination showed no axial rotation of the gastric conduit. The symptoms regressed gradually, and disappeared within two months post-operatively (Table 2). 
We recorded great improvement of the associated comorbidities. Thirty nine patients $(90.6 \%)$ out of forty three patients who had Type 2 diabetes mellitus stopped oral medications after normalization of the blood sugar level ( $p$-value $<0.001)$. Thirty four patients $(94.4 \%)$ out of thirty six patients with hypertension stopped anti-hypertensive medications ( $p$-value < 0.001). While twenty patients $(83.3 \%)$ out of twenty four patients with hyperlipidemia had normalization of their lipid profile during the post-operative course ( $p$-value $<0.001)$ (figure 3).
In terms of weight change, at six months, the BMI ranged from $30-60 \mathrm{~kg} / \mathrm{m}^{2}$ with a mean of $40 \pm 10.2$. While the $\%$ of EWL ranged between $27-63 \%$ with a mean of $51 \pm$ $12.3 \%$. At one year post-operatively, the BMI ranged from $26-37 \mathrm{~kg} / \mathrm{m}^{2}$ with a mean of $33 \pm 6.7$ (figure 4 ). While the \% of EWL ranged between $52-100 \%$ with a mean of $72 \pm 10.7 \%$. While at two years postoperatively, the BMI ranged from $24-35 \mathrm{~kg} / \mathrm{m}^{2}$ with a mean of $30 \pm 5.9$ (t-paired $=1.699$, p-value $<0.0001)$. While the \% of EWL ranged between $56-100 \%$ with a mean of $73 \pm 10.3 \%$ (figure 5 ).

Table (1) Demographic data of the patients contributing in our study

\begin{tabular}{|c|c|c|}
\hline Number of patients & $\mathrm{N}=140$ & \\
\hline Male / Female & $48 / 92$ & $\%=34 / 66$ \\
\hline Age (years) & Range $=17-58$ & Mean $=36 \pm 8.36$ \\
\hline BMI $\left(\mathrm{kg} / \mathrm{m}^{2}\right)$ & Range $=38-73$ & Mean $=49 \pm 7.4$ \\
\hline Weight (kg) & Range $=97-198$ & Mean $=112 \pm 27$ \\
\hline Co-morbidities: & Number of patients (n) & Percentage $(\%)$ \\
\hline Type 2 diabetes Mellitus & 43 & 30.7 \\
\hline Hypertension & 36 & 34.6 \\
\hline Hyperlipidemia & 24 & 17.1 \\
\hline Sleep apnea & 0 & 0 \\
\hline Symptomatic Osteoarthritis & 30 & 21.5 \\
\hline
\end{tabular}

Table ( 2): Intra and post-operative complications

\begin{tabular}{|c|c|c|}
\hline Operative time (minutes) & Range $=110-240$ & Mean $=124 \pm 12$ \\
\hline Intra operative complications: & Number of patients (n) & Percentage $(\%)$ \\
\hline Bleeding & 26 & 18.6 \\
\hline Organ injury & 10 & 7.1 \\
\hline Post-operative complications: & Number of patients (n) & Percentage $(\%)$ \\
\hline Fever & 6 & 4.2 \\
\hline Nausea and vomiting & 5 & 3.6 \\
\hline Chest infection & 8 & 5.7 \\
\hline Bleeding & 0 & 0 \\
\hline Wound infection & 0 & 0 \\
\hline DVT/pulmonary embolism & 2 & 1.4 \\
\hline Dysphagia / odynophagia & 15 & 10.7 \\
\hline Leakage & 3 & 2.1 \\
\hline Readmission rate & 5 & 3.6 \\
\hline Trocar site hernia & 0 & 0 \\
\hline Mortality & 0 & 0 \\
\hline Length of Stay (days) & Range $=1-4$ & Mean $=2.1 \pm 1$ \\
\hline
\end{tabular}




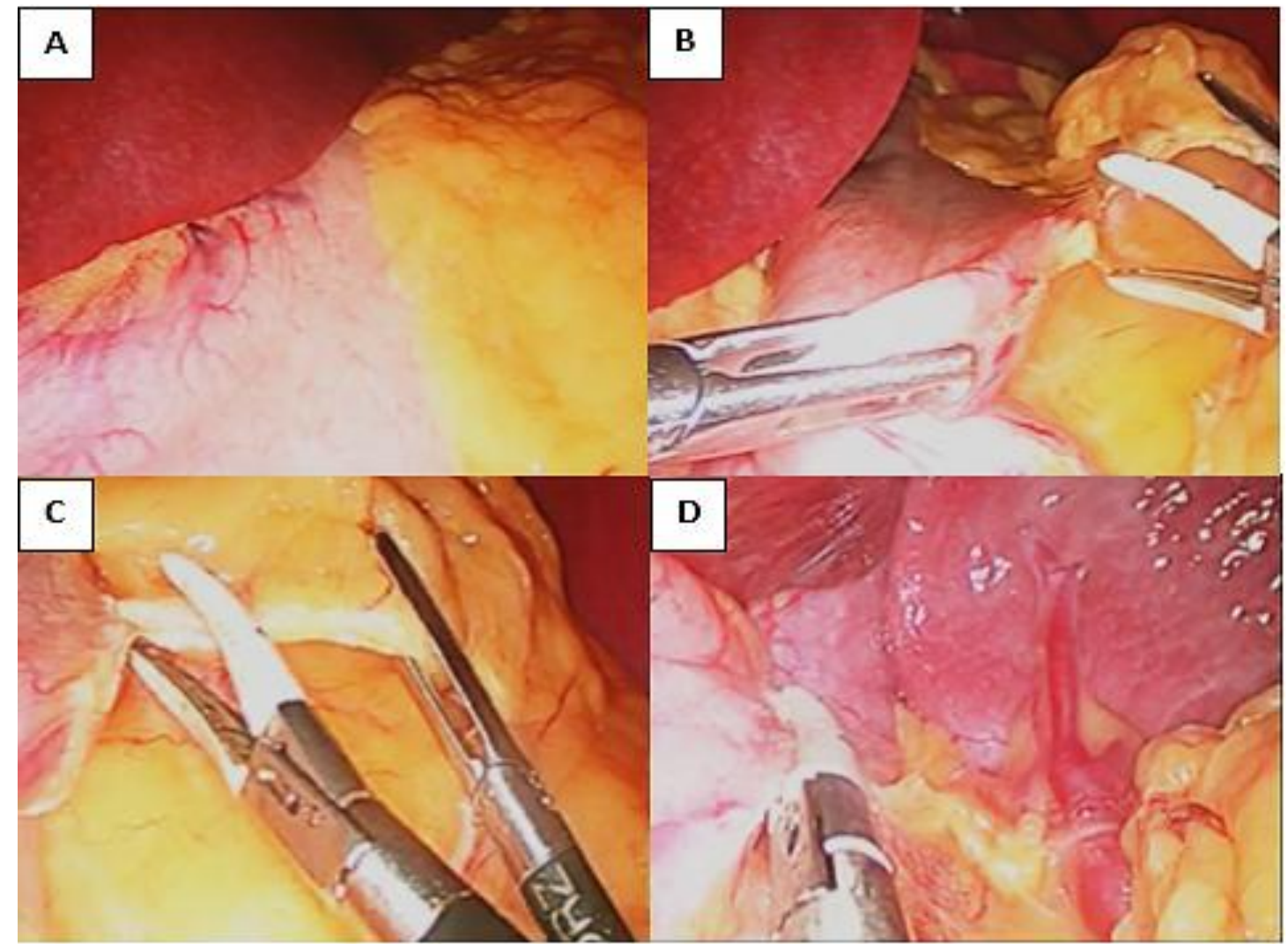

Figure (1): Dissection of the greater omentum from the stomach starting at $4 \mathrm{~cm}$ from the pylorus up to the angle of His.

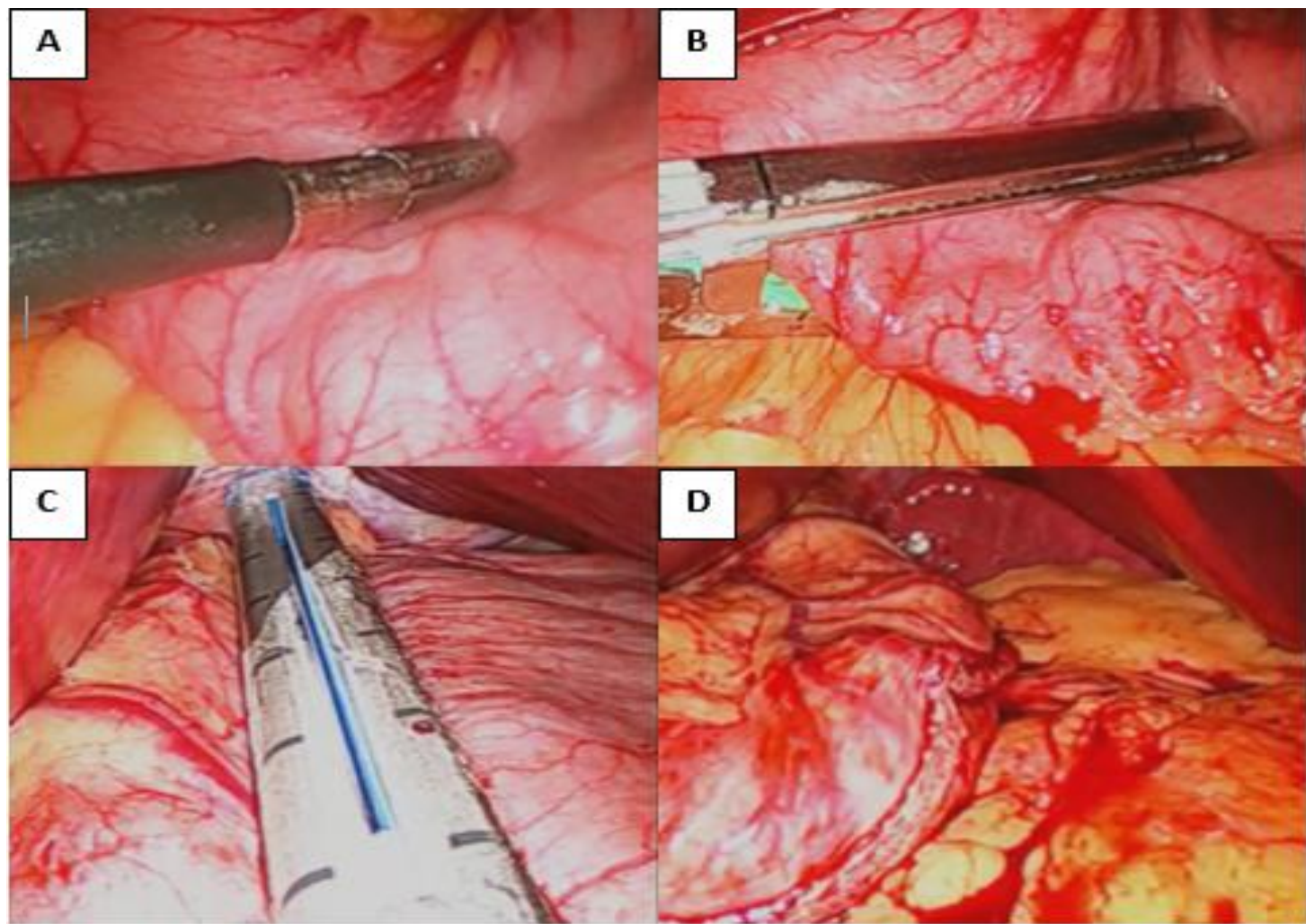

Figure (2): Creating gastric conduit using Endo GIA stapler over a 36 Fr bougie with partial antrectomy. 


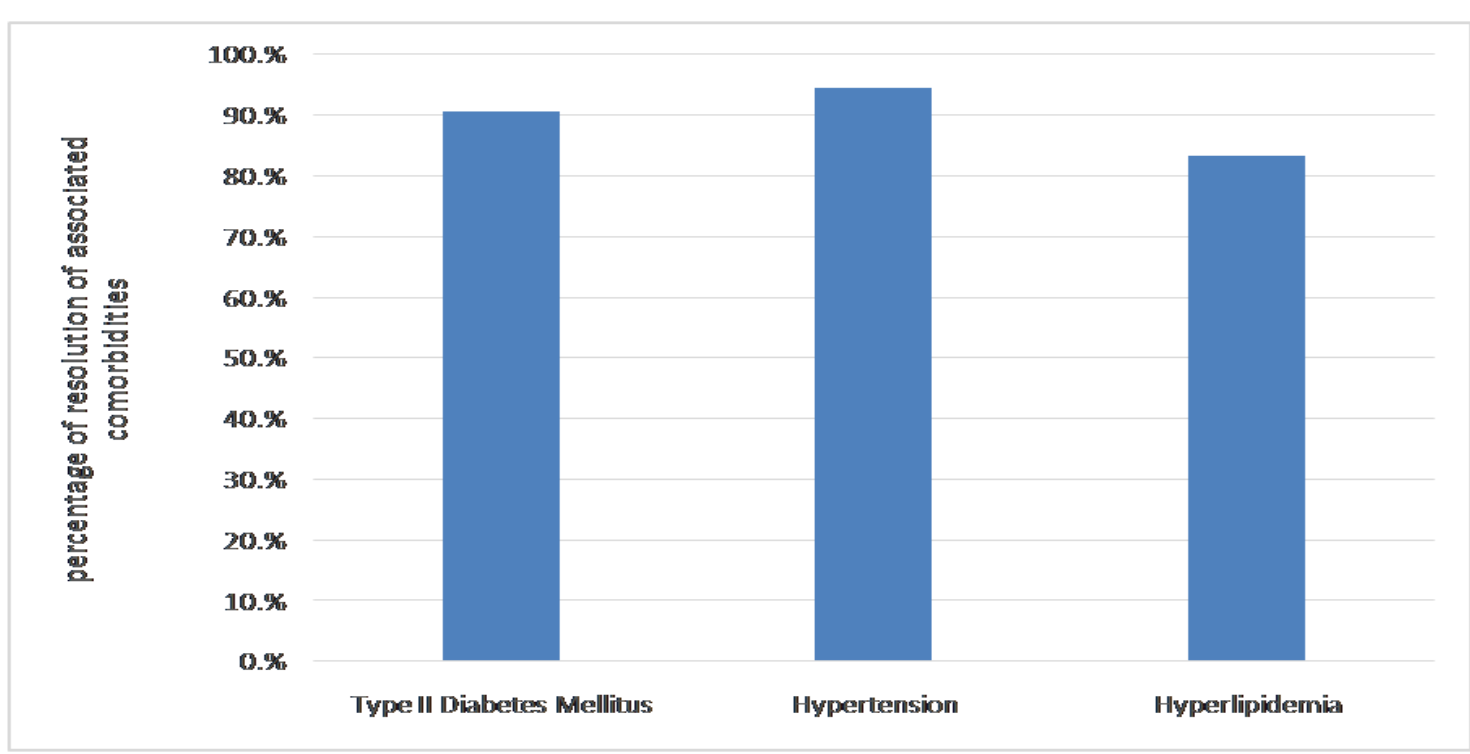

Figure (3): Percentage of Resolution of associated comorbidities after surgery with $p$ value $<0.0001$ for each of them

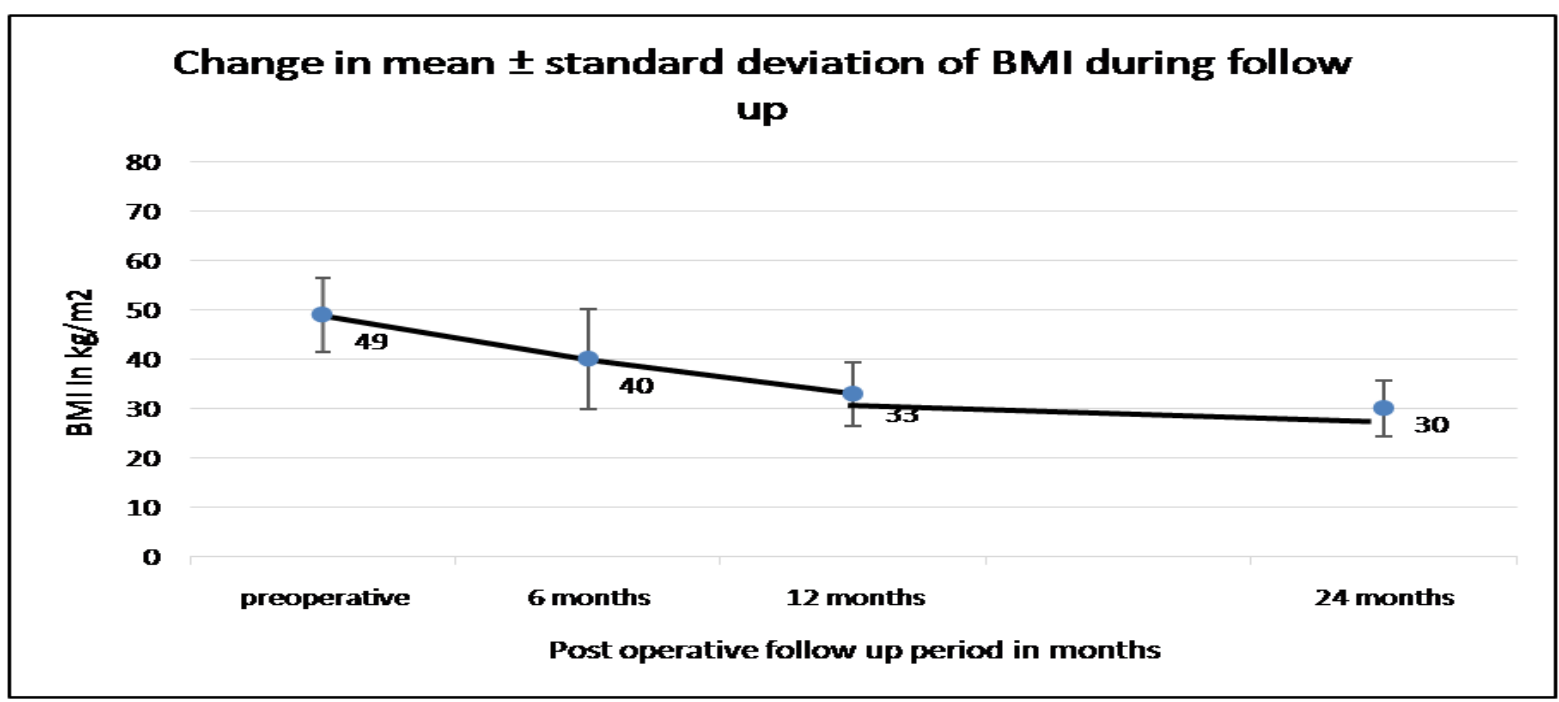

Figure 4: change in mean \pm SD of BMI before and after surgery

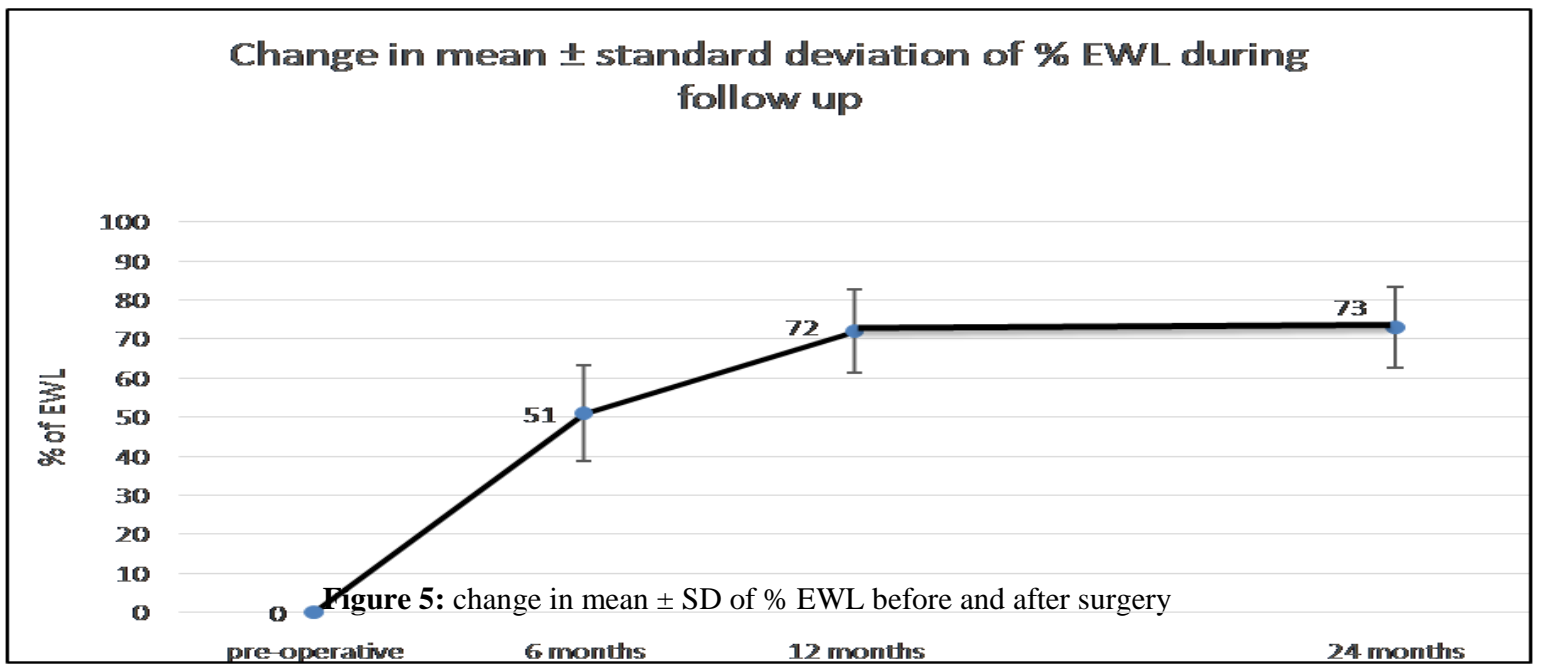

Figure (5): change in mean \pm SD of \% EWL before and after surgery 


\section{DISCUSSION}

The first one to perform LSG as a primary procedure for treatment of morbid obesity was Gagner in 1999. ${ }^{(12,13)}$ Since then, it gained a very good reputation all over the world, with many institutions adopting it as their primary bariatric procedure. Buchwald and Oien studied the change in the rate of bariatric surgeries performed worldwide in the period between 2003 and 2011. ${ }^{(14)}$ They founded between 2003 and 2008, there has been doubling of the number of the bariatric procedures performed all over the world, and that it has maintained that rate since then. They also found that LSG represented $0 \%$ of rate of bariatric procedures at 2003, then $5.3 \%$ in 2008, and 27.8 $\%$ in 2011. They showed that LSG is the rising star among bariatric procedures during the last decade, and that it is becoming the most popular bariatric procedure all over the world. This can be attributed to many factors, among them, the relative easiness of the technique, the excellent sustainable weight loss results, and the minimal malnutrition effects in comparison to the roux-en-y gastric bypass and the bilio-pancreatic diversion with duodenal switch. ${ }^{(15-17)}$ In addition, it needs no close, and tedious long-term follow up, and is associated with minimal vomiting, and superior \% of EWL in comparison to the adjustable gastric band. ${ }^{(18)}$ The main drawback of LSG was leakage from the staple line, and mainly just below the esophago-gastric junction. The causes were studied by many authors and standardizations were incrementally established that led to significant decrease in the rate of leakage. ${ }^{(19-22)}$ These included avoidance of the use a very small size bougie $<32 \mathrm{Fr}$, the avoidance of narrowing of the gastric conduit at the level of the incisura to avoid distal stenosis. In addition, they included the avoidance of axial rotation of the conduit, the avoidance of aggressive dissection and devascularization at the posterior area of the upper sleeve, and the avoidance of thermal injuries to the stomach. ${ }^{(23,24)}$ The use of staple line reinforcement has been a controversial issue among the surgical community that has not been resolved. ${ }^{(25-28)}$

We applied these surgical recommendations to our patients as much as we could. One hundred and forty patients contributed in our study. In our study, LSG was followed by significant decrease in BMI to $40 \pm 10.2,33$ \pm 6.4 , and $30 \pm 5.9 \mathrm{~kg} / \mathrm{m} 2$ at 6 months, one year, and two years post-operatively respectively. In addition, there was significant increase in \% of EWL to $51 \pm 12.3,72 \pm 10.7$, and $73 \pm 10.3 \%$ at 6 months, one year, and 2 years of follow up. LSG was associated with improvement of the co-morbidities related to morbid obesity. This included $90.6 \%$ resolution of Type 2 diabetes, $94.4 \%$ resolution of hypertension, and $83.3 \%$ resolution of hyperlipidemia. We had minor post-operative complications except for five cases. Three had leakage from the gastric conduit that was treated endoscopically and radiologically without further surgical intervention. While two cases had pulmonary embolism that required hospitalization and LMW heparin. There was no mortality among our patients. our results are comparable to those in the literature.
Gentileschi conducted a study on two hundred patients who underwent LSG between 2006 and 2011 with a median follow up period 27.2 months. The median BMI decreased from $49.4 \mathrm{~kg} / \mathrm{m} 2$ pre-operatively to a median of $30.4 \mathrm{~kg} / \mathrm{m} 2$. The median \% EWL was 63.6 at the end of follow up. He reported six major post-operative complications, in the form of two cases of gastric leak, three major bleedings and one case of bowel obstruction. There was only one case of mortality. ${ }^{(29)}$

Casella et al, studied the long-term effects of LSG their retrospective analysis of prospectively collected data of one hundred and eighty two patients we performed the procedure between 2006 and 2008. They studied outcomes over seven years after surgery in terms of weight changes and resolution of co-morbidities. The mean BMI was $30,28.7$, and $30.2 \mathrm{~kg} / \mathrm{m} 2$ at one, two and seven years respectively, and the \% of EWL was 70.4, 75.8, and $67.3 \%$ at one, two, and seven years respectively. The reported remission of Type 2 diabetes, arterial hypertension, Obstructive sleep apnea in $83.8 \%$, $59.7 \%$, and $75.6 \%$ respectively. ${ }^{(30)}$

In an interesting study by Bellanger and Greenway, LSG was performed to 529 morbidly obese patients with a mean BMI of $44.26 \pm 8.5 \mathrm{~kg} / \mathrm{m} 2$ between 2006 and 2010 . The $\%$ of EWL were 42.36, 65.92, 66.11, and 64.42 at 6 months, 1 year, 2, and 3 years, respectively. They reported zero cases of staple line leak. They attributed these results to several technical factors while doing the operation. They avoided thermal injuries by the sealing device. They applied the first staple cartilage tangentially from the right lateral port, at a distance one and half times from the $34 \mathrm{Fr}$ bougie to avoid stenosis at the incisural level. They allowed tissue compression by strokes of the stapler before firing, and waited ample time before release to allow stabilization of the stables into the tissues. They applied the last staple cartilage at a distance of $1 \mathrm{~cm}$ lateral to the angle of His. ${ }^{(31)}$

\section{CONCLUSION:}

Laparoscopic sleeve gastrectomy is becoming the most widely performed primary bariatric procedure. Our study shows that the procedure is easy, feasible and effective, during the short and intermediate terms as regards decrease in BMI, \% EWL, and resolution of morbid obesity associated co-morbidities. The procedure is associated with minimal complication rate. Longer follow up period is required to report the long-term effectiveness.

\section{REFERENCES:}

1. http://www.who.int/mediacentre/factsheets/fs311/en/.

2. Arroyo-Johnson C, Mincey KD. Obesity Epidemiology Worldwide. Gastroenterol Clin North Am. 2016 Dec; 45(4):571-579. doi: 10.1016/j.gtc.2016.07.012.

3. Hruby A, Hu FB. The Epidemiology of Obesity: A Big Picture. Pharmacoeconomics. 2015 Jul;33(7):673-689. doi: 10.1007/s40273-014-0243-x. 
4. Chan RS, Woo J Prevention of overweight and obesity: how effective is the current public health approach. Int $\mathbf{J}$ Environ Res Public Health. 2010; 7(3):765-783. doi: 10.3390 /ijerph7030765.

5. Silecchia G, Boru C, Pecchia A, Rizzello M, Casella G, Leonetti F, et al., Effectiveness of laparoscopic sleeve gastrectomy (first stage of biliopancreatic diversion with duodenal switch) on co-morbidities in super-obese highrisk patients. Obesity Surgery. 2006; 16 (9)1:1138-44.

6. Tucker ON, Szomstein S, Rosenthal RJ. Indications for sleeve gastrectomy as a primary procedure for weight loss in the morbidly obese. Journal of Gastrointestinal Surgery. 2008; 12(4):662-7.

7. Frezza EE. Laparoscopic vertical sleeve gastrectomy for morbid obesity. The future procedure of choice? Surgery Today. 2007; 37(4):275-81.

8. ME Abd Ellatif, E Abdallah, W Askar, W Thabet, M Aboushady, AE Abbas, et al. Long term predictors of success after laparoscopic sleeve gastrectomy. Int J Surg. 2014; 12(5):504-8. doi: 10.1016/j.ijsu. 2014. 02.008.

9. Benaiges D, Ma's-Lorenzo A, Goday A, Ramon JM, Chillaro'n JJ, Pedro-Botet J, Flores-Le Roux JA. Laparoscopic sleeve gastrectomy: more than a restrictive bariatric surgery procedure? World J Gastroenterol. 2015; 21(41):11804-14. doi: 10.3748/wjg. v21.i41. 11804.

10. Fried M, Yumuk V, Oppert JM, Scopinaro N, Torres AJ, Weiner R, Yashkov Y, Frühbeck G. Interdisciplinary European Guidelines on metabolic and bariatric surgery. European Association for the Study of Obesity; International Federation for the Surgery of Obesity European Chapter. Obes Facts. 2013; 6(5):449-68. doi: $10.1159 / 000355480$.

11. K singh, Laparoscopic Sleeve Gastrectomy: A Staged Procedure for Super-Super Obese Patients In: Nguyen NT, DeMaria EJ, Ikramuddin S, Hutter MM. The SAGES Manual A Practical Guide to Bariatric Surgery. Springer Science+Business Media, LLC. 2008: pp 131-5.

12. Regan JP, Inabnet WB, Gagner M. Early experience with two stage laparoscopic Roux-en-Y gastric bypass as an alternative in the super-super obese patient. Obes Surg. 2003; 13(6):861-4.

13. Milone L, Strong V, Gagner M. Laparoscopic sleeve gastrectomy is superior to endoscopic intragastric balloon as a first-stage procedure for super-obese patients (BMI $\geq 50)$. Obes Surg. 2005; 15(5):612-7.

14. Buchwald H, Oien DM. Metabolic/bariatric surgery worldwide 2011. Obes Surg. 2013; 23:427-36. doi: 10.1007/ s11695- 012-0864-0.

15. Dietel M, Crosby RD, Gagner M. The First International Consensus Summit for Sleeve Gastrectomy (SG), New York City, October 25-27, 2007. Obes Surg. 2008; 18:487-96.

16. Karamanakos SN, Vegenas K, Kalfarentzos F, et al. Weight loss, appetite suppression, and changes in fasting and postprandial ghrelin and peptide-YY levels after Roux-en-Y gastric bypass and sleeve gastrectomy; a prospective, double blind study. Ann Surg. 2008; 247:401-7.

17. Ren CJ, Patterson E, Gagner M. Early results of laparoscopic biliopancreatic diversion with duodenal switch: a case series of 40 consecutive patients. Obesity Surgery. 2000; 10:514-23. [PubMed: 11175958]

18. Hutter MM, Schirmer BD, Jones DB, KO CY, Cohen ME, Merkow RP, Nguyen NT. First Report from the American College of Surgeons - Bariatric Surgery Center Network: Laparoscopic Sleeve Gastrectomy has Morbidity and Effectiveness Positioned Between the Band and the Bypass. Ann Surg. 2011 September; 254(3): 410-22. doi:10.1097/SLA.0b013e31822c9dac.

19. Tan J, Kariyawasam S, Wijeratne T, and Chandraratna HS. Diagnosis and management of gastric leaks after laparoscopic sleeve gastrectomy for morbid obesity. Obesity Surgery. 2010; 20 (4):403-9.

20. Oshiro T, Kasama K, Umezawa A, Kanehira E, Kurokawa Y. Successful management of refractory staple line leakage at the esophagogastric junction after a sleeve gastrectomy using the HANAROSTENT. Obes Surg. 2010 Apr; 20(4):530-4. doi: 10.1007/s11695-0099976-6.

21. Jurowich C, Thalheimer A, Seyfried F, Fein M, Bender G, Germer CT, Wichelmann C. Gastric leakage after sleeve gastrectomy-clinical presentation and therapeutic options. Langenbecks Arch Surg. 2011 Oct; 396(7):9817. doi: 10.1007/s00423-011-0800-0.

22. Benedix F, Benedix DD, Knoll C, Weiner R, Bruns C, Manger T, Stroh C; Obesity Surgery Working Group.; Competence Network Obesity. Are there risk factors that increase the rate of staple line leakage in patients undergoing primary sleeve gastrectomy for morbid obesity? Obes Surg. 2014 Oct; 24(10):1610-6. doi: 10.1007/s11695-014-1257-3.

23. Abou Rached A, Basile M, ElMasri H. Gastric leaks post sleeve gastrectomy: Review of its prevention and management. World J Gastroenterol. 2014; 20(38): 13904-10. doi: 10.3748/wjg.v20.i38.13904

24. Rosenthal RJ, Diaz AA, Arvidsson D, Baker RS, Basso $\mathrm{N}$, Bellanger D, Boza C, El Mourad H, France M, Gagner $\mathrm{M}$, et al. International Sleeve Gastrectomy Expert Panel Consensus Statement: best practice guidelines based on experience of $>12,000$ cases. Surg Obes Relat Dis. 2012; 8:8-19.

25. Angrisani L, Cutolo PP, Buchwald JN, McGlennon TW, Nosso G, Persico F, Capaldo B, Savastano S. Laparoscopic reinforced sleeve gastrectomy: early results and complications. Obes Surg. 2011; 21:783-93.

26. Knapps J, Ghanem M, Clements J, Merchant AM. A systematic review of staple-line reinforcement in laparoscopic sleeve gastrectomy. JSLS. 2013 Jul-Sep; 17(3): 390-9. doi: 10.4293/ 108680813X13654754534639.

27. Gagner M, Buchwald JN. Comparison of laparoscopic sleeve gastrectomy leak rates in four staple-line reinforcement options: a systematic review. Surg Obes Relat Dis. 2014 Jul-Aug; 10(4):713-23. doi: 10.1016/j. soard.2014.01.016.

28. Parikh M, Issa R, McCrillis A, Saunders JK, UdeWelcome A, Gagner M. Surgical strategies that may decrease leak after laparoscopic sleeve gastrectomy: a systematic review and meta-analysis of 9991 cases. Ann Surg. 2013 Feb; 257(2):231-7. doi: 10.1097/ SLA.0b013e31826cc714. PMID: 23023201. 